\section{Questión}

Periodismo / Comunicación ISSN 1669-6581
- Av. $44 \mathrm{~N}^{\circ} 676,1^{\circ}$ piso

CP 1900 - La Plata - Argentina

(i) www.perio.unlp.edu.ar/question

Periodismo de Soluciones

Jaime Beltrán Villalobos

DOI: https://doi.org/10.24215/16696581e318

\title{
Periodismo de Soluciones
}

\section{Solutions Journalism}

Jaime Beltrán Villalobos / jbeltran@fundaciongabo.org Coordinador de Proyectos de la Fundación Gabo.

Seminario web "Periodismo de Soluciones. ¿Cómo cubrir el coronavirus más allá de la desesperanza? Por Liza Gross en el marco del Proyecto "Periodismo de Soluciones en América Latina" organizado por Fundación Gabo (Colombia) y la Red de Periodismo de Soluciones.

Liza Gross es periodista, experta en medios y representante del Solutiones Journalism Network. Fue editora The Miami Herald y Directora Ejecutiva de Internacional Women's Media Foundation.

En este seminario web, reflexionó sobre cómo cubrir los temas del Covid-19, no solo investigando las consecuencias y llevando un registro del caos, sino también sobre posibles guías para pensar y exponer posibles soluciones para la actual crisis.

https://www.youtube.com/watch?v=Pxqbesa2Dg8\&t=18s

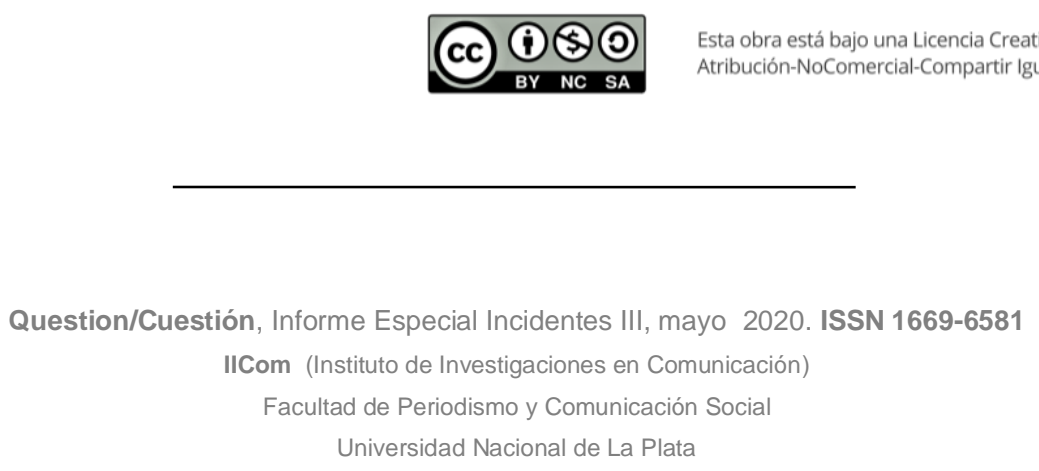

